as students are obliged to attend two of his conrses, his clear gains are six times more than any other from each student who pursues his whole course in the Queen's Colleges, while his salary is double that of his colleagues. This does not seem intelligible, but it is a fact, however. Those of the four professors I have mentioned, who had the misfortune to give up their connexions and chance of rising by knowledge and industry in practice, on accepting professorships far away from where they were known, have little chance of obtaining practice in the provinces, where, as you well know, obvious poverty is a bad introduction; and that their poverty must be obvious is clear enough, when they have, out of $£ 100$ a year, to provide a decent coat to lecture in, (to say nothing of expensive academical robes,) to keep a lodging without a thatched roof, and to support (?) themselves, and perhaps a family, and pay $£ 5$ per annum income-tax !

If the State were to give $£ 200$ a year to those medical professors who have at present but half that sum, it would put them at least above indigence, relieve them from the hardship of trying to look as like gentlemen as possible on a butler's wages, it would be just and sensible, as well as humane, and, I have no doubt, would give perfect content to the recipients; while the additional charge on the treasury, for the three Colleges, would be only $£ 1200$ a year.

I am, Sir, your obedient servant,

October, 1856.

M.D.

\section{DR. BROOKES' CASE OF INGUINAL ANEURISM.}

To the Editor of THE LANCET.

SIR,-OOn perusing the above case, in THE LANCET of August $16 \mathrm{th}$, I could not help noticing the extraordinary features of the case, which necessarily lead to a few remarks. 1st. Was it an aneurism at all ? 2ndly. If an aneurism, was the artery tied?

In the first place, then, was it an aneurism? The vacillating character of the tumour, the nature of the injury, the acute pain, and the length of time before any pulsation was discovered, cast a doubt upon the correctness of the diagnosis. The patient was a man whose occupation rendered him particularly liable to injury of the inguinal glands : might not the glands, becoming inflamed and enlarged, and lying over the artery, account for the pulsating tumour, so readily discovered by Mr. Gregory, who, possessing the tactus eruditus to an extraordinary degree, was enabled to arrive at a correct diagnosis without further trouble? Is it usual for an aneurismal tumour to disappear altogether a few hours after the application of a ligature; to return again afterwards, alter its position, and finally be discharged by suppuration?

Secondly,-Was the artery tied! Perhaps Dr. Brookes will be kind enough to inform us of the changes which take place in an artery after the application of a ligature: how an aneurismal sac could inflame beyond its own limits-viz., down to the inferior third of the thigh ? Might not the tendon of the psoas, or a portion of pelvic fascia, have been mistaken for the artery, and a ligature placed upon it? The undiminished temperature of the limb, the length of time before the ligature came away, (not until the fortieth day,) and the consequent suppuration of the sac, certainly favour that supposition; unless, indeed, Nature was effecting a spontaneous cure by suppuration, and the artery, participating in the inflammation, became closed by effusion of lymph, or by coagulation of blood within it, and thereby rendering the operation useless.

I am, Sir, your obedient servant,

Chipping Campden, Sept. 1856.

Fred. H. Morris.

\section{(O)lituatw.}

\section{DR. SAMUEL EDWARDS.}

IT is with great regret that we record the death of Dr. SAMued EDwards, late of Upper George-street, Bryanstonsquare, who died of pulmonary phthisis, on the 30th ult., at Newport, near Barnstaple, Devonshire, whither he had gone with the hope of being benefited by change of air.

Dr. Edwards was the youngest son of a city merchant, who resided at Peckham. He was born March 31st, 1822, and received the chief of his education at a collegiate school at Peckham, then under the mastership of Mr. Reid. When a boy, he was delicate, and suffered much from a painful and obscure affection of the heart, for which he was sent to Boulogne, where he for some time resided, and with much benefit. An elder brother had practised as a surgeon in London, who, like the subject of our notice, was, at an early age, cut off by the same disease. Samuel, by chance, perused some of the medical works which belonged to that brother, and this led him to embrace medicine as a profession. He was articled to Mr. Huxtable, a gentleman who had a large practice in Hackney. The pupil soon gave evidence of his partiality to study, and of his natural aptness for the calling he had espoused.

In Nov., 1840, he repaired to Edinburgh, and entered the college classes, not then with a view to graduation, but in order to sit under the prelections of the best teachers. His studious mind had now an ample field for exertion, and he devoted himself to his pursuits with a zeal that nothing but a natural love for his vocation could have inspired. During his first and second sessions, he formed a small circle of acquaintance amongst his fellow students, and with some of whom that acquaintance ripened into a lasting friendship. Three or four of these early associates settled in London, and the intimacy was continued with an unusual friendliness and frequent intercourse to the day of his death. London is happily a field too vast for those jarring interests and petty jealousies which too often obtain amongst the members of our art when in juxtaposition in smaller communities. He took several prizes during his curriculum, which was completed at Edinburgh, and many of the lecturers were very favourably impressed with his acquirements. During the winter of $1842-43$, he was appointed by Professor Simpson as interne at the Lying-in Hospital, then in Park-square. The duties of that post he discharged with considerable credit. Not only did Dr. Simpson entertain a high opinion of his talents, but the students looked up to him as one, at his time of life, unusually versed in the obstetric art. He gained a medal in Dr. Simpson's class for commentaries on a series of cases, all of which he had superintended; and these essays were spoken of as very meritorious. He now resolved to practise as a physician; but as he had not passed anni medici by matriculating at Edinburgh, he could not then take his degree, and consequently he graduated at St. Andrew's, in May, 1843 .

In 1844 he married, and at the early age of twenty-two settled as a physician at Bath. He was soon afterwards appointed as physician to the Eye and Ear Infirmary of that city, and to the diseases incident to these organs he paid particular attention, ever after taking a more than common interest in their phenomena. He remained at Bath till the spring of 1848, when he resolved to remove to the metropolis. The consulting practice in a town no larger than Bath is, as a matter of course, but limited, and unless by death or retirement a vacancy occasionally occurs, the junior practitioner may have long to wait before he comes into a remunerative practice. It was under such consideration that he came to the capital, notwithstanding his being urged to remain, and assured of ultimate success.

When he came to London, he joined Mr. Gray, of Upper George-street, in general practice, from which $\mathrm{Mr}$. Gray shortly afterwards, from ill health, retired. In conjunction with this gentleman and others, he exerted himself in the establishment of the Marylebone Institute for the Diseases of Women. To this charity he was subsequently appointed physician, and Mr. Gray the surgeon. The latter resigned, and Mr. Wells became his successor. Dr. Edwards soon grew tired of general practice, and determined on the resumption of his practice as a physician. He devoted himself with his wonted zeal to his dispensary practice, and this gaveample means for the prosecution of inquiries in those branches of the healing art with which, from his connexion with Dr. Simpson, he had essayed to become thoroughly familiar. He took careful notes of every patient under his care, and more especially of all those presenting any form of uterine affection. His labours at the above charity were most assiduous, and numbers of the poor, not only in the neighbourhood, but from distant parts, derived lasting benefit from his intelligence and philanthropy. In 1854, an arrangement was made by the committee of management for the incorporation of the Marylebone Institute for the Diseases of Women with the Samaritan Hospital. After their union, Dr. Edwards was elected the physician-accoucheur, which appointment he held to the time of his decease. He was the author of several papers, published in this and other journals, on subjects connected with obstetric medicine, and all his writings are characterized by clearness of perception and originality of thinking. Shortly before the supervention of that attack which went on to a fatal termination, he mentioned it as his intention to write 